\title{
De problema de família a problema social: notas etnográficas sobre o desaparecimento de pessoas no Brasil contemporâneo
}

From family issue to social issue: ethnographic notes

on missing persons in contemporary Brazil

\section{Letícia Carvalho de Mesquita Ferreira}

\section{(2) OpenEdition Journals}

\section{Edição electrónica}

URL: http://journals.openedition.org/aa/426

DOI: $10.4000 /$ aa. 426

ISSN: 2357-738X

\section{Editora}

Programa de Pós-Graduação em Antropologia Social (UnB)

\section{Edição impressa}

Data de publição: 1 junho 2013

Paginação: 191-216

ISSN: 0102-4302

\section{Refêrencia eletrónica}

Letícia Carvalho de Mesquita Ferreira, «De problema de família a problema social: notas etnográficas sobre o desaparecimento de pessoas no Brasil contemporâneo», Anuário Antropológico [Online], v.38 n. 1 | 2013, posto online no dia 01 outubro 2013, consultado o 28 abril 2021. URL: http:// journals.openedition.org/aa/426 ; DOI: https://doi.org/10.4000/aa.426

\section{@(@) $\Theta \Theta$}

Anuário Antropológico is licensed under a Creative Commons Atribuição-Uso Não-Comercial-Proibição de realização de Obras Derivadas 4.0 International. 


\section{De problema de família a problema social: notas etnográficas sobre o desaparecimento de pessoas no Brasil contemporâneo}

Letícia Carvalho de Mesquita Ferreira

$\mathrm{CPDOC} / \mathrm{FGV}$

Daniela, auxiliar de serviços gerais, tem 22 anos de idade e duas filhas: Fabiane e Flaviane. ${ }^{1}$ Fabiane tem 8 anos e Flaviane, 3. Dia 26 de abril de 2007, Daniela deixou a primogênita na casa de Fábio, pai da criança, e a caçula na casa de sua mãe, Magda. Saiu da casa de Magda dizendo que visitaria uma amiga e logo retornaria, mas nunca mais foi vista, nem deu notícias.

Em outubro daquele ano, Magda foi a uma delegacia de polícia (DP) reportar o fato. Seus relatos deram origem a um registro de ocorrência intitulado desaparecimento de pessoa. No documento, Magda consta como comunicante, e Daniela, como desaparecida. Na DP, Magda disse ao policial que a atendeu que nos últimos meses procurara pela filha em casas de amigos e parentes, sem sucesso. Relatou ainda que, ao partir, Daniela havia deixado o endereço de onde estaria. Ao procurar pelo endereço, no entanto, Magda constatara que

o mesmo não existia e assim voltou à estaca zero na tentativa de localizar a referida DESAPARECIDA, e mesmo assim ainda procurou por hospitais e demais órgãos públicos e sem mais locais a procurar e esperando notícias da mesma, que não tem até a presente data, comparece a esta delegacia de polícia (SDP/DH 030/07).

Já em 2008, o caso de Daniela foi encaminhado para o Setor de Descoberta de Paradeiros (SDP) da antiga Delegacia de Homicídios (DH) do Rio de Janeiro Centro/Capital - setor desta delegacia dedicado exclusivamente a investigar casos de desaparecimento. A primeira providência do policial do Setor que ficou encarregado do caso foi telefonar para Magda. A partir do telefonema, o agente decidiu arquivar o caso, com a seguinte justificativa: 
deve ter ocorrido algum problema familiar que fez com que DANIELA saísse de casa, já que segundo a comunicante sua filha ligou no carnaval deste ano dizendo que iria aparecer, mas que infelizmente até a presente data não foi visitar a mãe (SDP/DH 030/07).

\section{Introdução}

Daniela protagoniza um dos milhares de casos de desaparecimento comunicados anualmente a DPs brasileiras. Consideravelmente heterogêneos em seus enredos, casos de desaparecimento são protagonizados por idosos acometidos por perdas temporárias ou definitivas de memória, adolescentes que fogem de casa ou de abrigos e outras instituições públicas, adultos que optam por deixar suas casas, empregos e rotinas, além de vítimas fatais de acidentes, calamidades ou crimes cujos cadáveres não são localizados. A despeito das diferenças que separam os casos, seus protagonistas são invariavelmente designados por policiais, conselheiros tutelares, militantes de movimentos sociais, gestores de políticas públicas e cientistas sociais como desaparecidos. ${ }^{2}$ Em conjunto, as experiências por eles vividas são encaradas como manifestações particulares de um só fenômeno, visto como passível de combate: o desaparecimento de pessoas.

O desaparecimento de pessoas é objeto de campanhas de conscientização, projetos de prevenção e serviços de atendimento e assistência, governamentais e não governamentais, oferecidos sem diferentes cidades e estados brasileiros. Ademais, é matéria recorrente de noticiários e reportagens amplamente divulgadas por meios de comunicação de massa, tema de alguns artigos, teses e pesquisas acadêmicas (cf. Oliveira, D.D., 2007; Oliveira, S.R., 2008; Ferreira, 2011), e ainda objeto de investigações, investimentos e iniciativas levadas a cabo em diferentes níveis da administração pública, como, por exemplo, a Comissão Parlamentar de Inquérito que ficou conhecida como "CPI das Crianças e Adolescentes Desaparecidos”, instaurada na Câmara dos Deputados em dezembro de 2009 (Brasil, 2010).

Não obstante, o desaparecimento é um tipo de ocorrência policial registrado e gerido rotineiramente em delegacias como fato de menor importância. Ainda que policiais se dediquem a investigar casos, atender a familiares de desaparecidos e registrar declarações de comunicantes, não é sem muito questionar e colocar em dúvida suas atribuições e responsabilidades diante desse fenômeno que o fazem (cf. Oliveira, D.D., 2007; Ferreira, 2011). Para policiais, desaparecimentos de pessoa são problemas de família, cujas causas, responsabilidades e possibilidades de solução encontram-se no interior de unidades domésticas, arranjos familiares e parentelas - e não em repartições policiais. Devem, nesse 
sentido, ser geridos e solucionados pelos próprios familiares dos desaparecidos. À polícia caberia apenas registrá-los e, no mais das vezes, arquivá-los sumariamente, como ocorrido no caso de Daniela.

O presente artigo tem por objetivo compreender a construção do desaparecimento de pessoas, no Brasil contemporâneo, como um problema social - isto é, como causa pública de engajamento e debate, tratada como problemática no tocante às formas de gestão e enfrentamento de que dispomos no país. ${ }^{3}$ Levando em conta a classificação de casos em delegacias como problemas de família que não demandam atuação policial, meu propósito é analisar como esse fenômeno ganha o estatuto de questão grave, urgente e que requer amplo engajamento por parte de diferentes atores e órgãos de administração pública. Se na lida cotidiana com casos como o de Daniela policiais eximem-se de responsabilidades de investigação, como o desaparecimento de pessoas ganha relevância a ponto de ser objeto de debates públicos, notícias veiculadas por meios de comunicação de massa e até uma CPI? No mesmo sentido, se o fenômeno goza de tamanha relevância, como é possível o arquivamento sumário de casos particulares em repartições policiais?

O texto é resultado de uma etnografia multissituada iniciada no Setor de Descoberta de Paradeiros (SDP) da Delegacia de Homicídios (DH) do Rio de Janeiro e, em seguida, estendida para eventos promovidos pela Rede Nacional de Identificação e Localização de Crianças e Adolescentes Desaparecidos (ReDesap). ${ }^{4}$ O SDP é o setor da Polícia Civil do Rio de Janeiro em que o caso de Daniela se encontra arquivado. A equipe que trabalha no Setor é composta por cinco inspetores de Polícia Civil, e executava suas tarefas, durante o período de realização da pesquisa, em uma sala da antiga Delegacia de Homicídios do Rio de Janeiro Centro/Capital, hoje Divisão de Homicídios. Desenvolvida entre março de 2008 e dezembro de 2009, a pesquisa no Setor consistiu em acompanhar a rotina da equipe e, indissociavelmente, analisar documentos por ela produzidos e arquivados.

Em linhas gerais, as tarefas dos cinco inspetores do SDP consistem em investigar casos de desaparecimento registrados em delegacias comuns (da $1^{\mathrm{a}} \mathrm{DP}$ à $44^{\mathrm{a}}$ DP) da capital do estado do Rio de Janeiro. As delegacias que registram os casos têm 15 dias para investigá-los e dar-lhes desfecho. Extinto esse prazo, centraliza-se no SDP a competência e a responsabilidade por todos os desaparecimentos comunicados às DPs (Rio de Janeiro, 1991). As investigações em torno de cada caso originam documentos que são arquivados, organizados e contabilizados no próprio SDP. Em setembro de 2008, o Setor arquivava documentos relativos a 9.293 pessoas que desapareceram, algumas delas mais de uma vez, desde o ano de 1993. 
A ReDesap, por sua vez, é uma instância de debates e formulação de estratégias de enfrentamento ao desaparecimento de pessoas que articula 47 instituições, entre organizações não governamentais (ONGs) e órgãos de administração pública, como conselhos tutelares, delegacias de polícia e a Secretaria de Direitos Humanos da Presidência da República (SDH/PR). Entre elas, há organizações que lidam exclusivamente com desaparecimentos de crianças e adolescentes, como os chamados "SOS Crianças Desaparecidas", e outras que lidam com uma gama mais variada de questões atinentes à infância e adolescência, como delegacias especializadas em crimes contra crianças e adolescentes. Não obstante, também integram a rede organizações cuja atuação não se restringe a casos de crianças e adolescentes, como as ONGs Mães em Luta e Mães da Sé, que prestam assistência a familiares de desaparecidos sem distinção de faixa etária, e ainda órgãos que lidam com casos de desaparecimento entre muitos outros afazeres e atribuições, como o Departamento de Homicídios e Proteção à Pessoa (DHPP) de São Paulo e a Defensoria Pública do estado do Rio de Janeiro.

Fundada em 2002, a rede é coordenada pela SDH/PR, e tem à sua frente um comitê gestor que se reúne com regularidade. Durante a realização da pesquisa, o comitê era composto por três delegados de Polícia Civil, a presidente de uma associação de familiares de desaparecidos, o gerente de um programa assistencial voltado para a busca de crianças desaparecidas e atendimento de seus familiares, uma representante do Fórum Colegiado Nacional de Conselhos Tutelares e, ainda, um gestor da SDH/PR. Anualmente, a rede promove um evento nacional e alguns encontros regionais abertos ao público interessado, e é nessas ocasiões que representantes das organizações que a integram se reúnem. Estive presente em 17 eventos promovidos pela ReDesap de dezembro de 2008 a novembro de 2010, entre reuniões do comitê gestor e encontros nacionais e regionais. No primeiro evento fui parte do público ouvinte. Nos demais, estive presente como convidada dos membros do comitê gestor, ora para participar das reuniões, ora para proferir palestras e compartilhar com eles resultados parciais da pesquisa então em curso (cf. Ferreira, 2011).

O trânsito entre o exíguo espaço do SDP e os amplos gabinetes e salões de convenção em que acontecem eventos da ReDesap foi o que me permitiu construir o objeto ora em análise. Foi o percurso entre o espaço da repartição e o espaço da rede, afinal, que me colocou em contato tanto com o tratamento policial de casos de desaparecimento quanto com a tomada do fenômeno como objeto de debate público. Em linhas gerais, esse percurso descortinou que, mais que um fenômeno consolidado e indisputado, o desaparecimento de pessoas é objeto de múltiplos embates: construído como problema social dotado de um 
incidental e controverso componente criminal, é classificado em repartições da Polícia Civil e em eventos da ReDesap, alternadamente, como problema de família, problema de polícia e/ou problema do Estado. O caso de Daniela, por exemplo, ilustra a primeira classificação, vigente especialmente entre policiais. Descrevendo as posições e as perspectivas de policiais e, ainda, de outros atores sociais envolvidos com a questão, como mães de desaparecidos e gestores de políticas públicas, no presente artigo explicito essa disputada concepção tripartite do que é o desaparecimento de pessoas. A hipótese sustentada é a de que a controvérsia em torno de seu caráter plural (de família, de polícia, do Estado) é fundamental para a constituição do desaparecimento como questão a ser combatida no Brasil.

\section{Arquivando problemas de família}

No cotidiano das DPs brasileiras, o desaparecimento de pessoas é classificado como "fato atípico", isto é, como espécie de ocorrência que não corresponde a qualquer tipo penal previsto pela lei brasileira. Não constitui crime, não possui materialidade, não prescreve em prazos determinados e não pode gerar inquérito policial. ${ }^{5}$ É, por essas razões, tratado somente em processos administrativos. Enquanto permanecem nas dependências das DPs do Rio de Janeiro, por exemplo, os documentos que compõem cada caso integram Verificações de Procedência de Investigação (VPI). Nesses documentos, desaparecidos figuram, por vezes, como vítimas, ao passo que familiares e conhecidos dos desaparecidos são denominados comunicantes, como vimos no caso de Daniela.

Não obstante, no cotidiano de Conselhos Tutelares, associações de familiares de desaparecidos e serviços públicos de assistência social, parentes, familiares e conhecidos de desaparecidos são recebidos, assistidos e classificados também como vítimas de casos de desaparecimento. Nessas instituições, parte-se da premissa de que os casos incidem dramaticamente sobre familiares e conhecidos dos desaparecidos, de modo semelhante ao que ocorre com as chamadas vítimas ocultas da violência urbana (Soares et al., 2006). Instituições que lidam diariamente com casos de desaparecimento, portanto, não abordam o fenômeno a partir de uma mesma gramática e, por isso, situam diferentes sujeitos na posição de vítimas.

Para além das abordagens de atores que lidam institucionalmente com o desaparecimento, tampouco operam uma mesma gramática os (poucos) estudiosos dedicados ao fenômeno. De modo excludente, há interpretações que classificam o desaparecimento como uma das faces da "violência urbana" (Espinheira, 1999), enquanto outras o encaram como consequência direta da "violência intrafamiliar” (Oliveira \& Geraldes, 1999) e de valores do patriarcalismo e seus 
impactos sobre relações de gênero e geração no interior de famílias brasileiras (Oliveira, 2007). Vistas em conjunto, essas interpretações constroem abordagens excludentes: em alguns trabalhos, as famílias de desaparecidos são encaradas como "instâncias produtoras de desaparecimentos" (Oliveira, 2007), ao passo que em outros são vistas como agentes passivos, que precisam ser protegidos pelos poderes públicos.

Durante a pesquisa no SDP e em eventos da ReDesap, tive contato com casos e enunciados que desafiam essa arrumação promovida pela literatura sobre o tema. Entre as ocorrências registradas pela Polícia Civil do Rio de Janeiro como desaparecimento, por exemplo, há de fato casos que enredam a chamada "violência intrafamiliar". Ao longo da pesquisa me foi relatado, dentre outros casos, que inspetores do SDP certa vez apuraram que um homem que comunicara o desaparecimento de sua esposa e filho recém-nascido havia agredido fisicamente aqueles que afirmou terem desaparecido. Nesse caso, a esposa deixara sua residência sem aviso e levando consigo o bebê para proteger-se (e à sua criança) de novos episódios de violência conjugal. Junto a casos deste tipo, porém, DPs lidam também com ocorrências que revelam se tratar de crimes como sequestro, homicídio e/ou ocultação de cadáver, encarados como manifestações da "violência urbana” na contemporaneidade. Exemplo notório é a chamada Chacina de Acari, cujas vítimas foram registradas em DPs como desaparecidos (Araújo, 2007; Nobre, 2005).

Ainda que haja exemplos como estes, uma coleção heterogênea de acontecimentos registrados em DPs como desaparecimentos escapa à dicotomia classificatória que separa casos decorrentes de "violência intrafamiliar" daqueles vistos como parte da "violência urbana". Os arquivos do SDP, bem como relatos de seus funcionários, não deixam dúvidas a este respeito. Dentre os casos arquivados no Setor, encontra-se o registro do desaparecimento de um homem que, enquanto era atendido em um hospital, sumiu do campo de visão de todos os profissionais que o atendiam e de sua mãe, que o acompanhava; dias depois, foi encontrado "caído pela rua na Praia de Ipanema" (SDP/DH 004/08) e levado para uma clínica psiquiátrica. Ao lado dos documentos acerca deste caso, encontra-se também o de uma jovem que, após ter fugido de casa algumas vezes, fugira novamente por estar "aborrecida com a vida, cansada e extremada" (SDP/ DH 020/08). Na mesma gaveta, por fim, há o caso comunicado por moradores de um edifício cujo síndico teria roubado o condomínio e desaparecido em seguida (SDP/DH 003/08), e o registro solicitado por uma mulher que afirmara que seu sobrinho "vivia vagando pelas ruas como pedinte" (SDP/DH 009/08).

Embora tão distintos entre si, esses casos foram igualmente registrados 
como desaparecimentos de pessoa. O que chama a atenção nessa coleção é que, de modo geral, as ocorrências não possuem componentes especificamente criminais, constituindo, nos termos de Mota (1995), "casos sociais" - isto é, questões e conflitos que escapam às definições jurídicas utilizadas no cotidiano das delegacias, cuja afluência a estas repartições reflete a falta de acesso a outros recursos institucionais experimentada pelas camadas pobres da população de cidades brasileiras. A especificidade dos "casos sociais" registrados como desaparecimento, entretanto, é que componentes criminais eventualmente se fazem presentes, não podendo ser excluídos a priori.

A presença eventual e por vezes apenas virtual de componentes criminais faz com que policiais não reconheçam o desaparecimento como parte constitutiva de suas atribuições profissionais. Assim como nas Delegacias Especiais de Atendimento à Mulher (DEAMs) estudadas por Soares (1999), repartições policiais que se dedicam a desaparecimentos são vistas como "delegacias de papel”, e têm sua importância posta em dúvida por seus próprios funcionários, entre outros policiais. "Delegacia de papel” ou "delegacia seca" é aquela que "não prende, não promove batidas, não desempenha ações espetaculares” (Soares, 1999:53), isto é, que lida mais com procedimentos burocráticos do que com operações de rua. Esta questão é, inclusive, um dos mais recorrentes objetos de reflexão no interior do SDP.

Segundo Fernando, inspetor que atua no SDP há quase 15 anos, embora o número de casos ali investigados seja alto, o trabalho do Setor não é valorizado, lida com condições precárias e é guiado por uma legislação falha e contraditória. O desaparecimento de pessoas, pela ótica de Fernando, não possui a visibilidade que merece, não recebe tratamento adequado pelas autoridades competentes e tampouco é de fato conhecido pelos cidadãos. Desconhecimento, tratamento inadequado e invisibilidade não se voltam apenas ao desaparecimento, mas projetam-se sobre o próprio SDP. Ademais, sobrepondo-se a esses problemas, para o inspetor, a grande dificuldade enfrentada no Setor é o fato de o desaparecimento não corresponder a qualquer tipo penal previsto pela lei brasileira e, entretanto, integrar o rol de ocorrências que ficam a cargo de policiais.

Ao refletir sobre o trabalho executado no SDP, Fernando afirma que muitas vezes faz algo parecido com "atendimento psicológico", embora não tenha nem formação, nem responsabilidade para isso. No curso de meu trabalho de campo no Setor, em diversas ocasiões, o inspetor me relatou que a maior parte dos casos que por ali passam enreda pessoas que deixaram suas casas sem intenção de retorno, embora suas famílias ainda os aguardem, não sem sofrimento. Disse também que, como espectador desse sofrimento, por vezes fornece o número 
de seu telefone celular para familiares de desaparecidos e se envolve realmente com os casos, "perdendo noites de sono", mas que a sensibilidade e a técnica necessárias para lidar com os dramas das famílias de desaparecidos são difíceis de serem desenvolvidas em função da precariedade de condições de trabalho que lhe são disponibilizadas.

Reflexões semelhantes me foram relatadas por Telma, inspetora que chefiou o SDP durante o período de minha pesquisa. Nas palavras dela, muitas das tarefas realizadas ali são "serviço de assistência social" voltado para as famílias de desaparecidos. Não obstante, esse "serviço" é especialmente complicado dado o fato de que“ as famílias podem mentir”.

Um de seus relatos, que evidenciaria tanto o caráter assistencial do "serviço" do Setor quanto a possibilidade da mentira por parte das famílias, é o caso de um senhor de avançada idade que foi registrado por seus vizinhos como desaparecido. As investigações do SDP permitiram concluir que os vizinhos solicitaram o registro para que a polícia tomasse conhecimento de que ele vinha sendo explorado por uma jovem, que passara a morar em sua residência e a ter acesso a seus bens. Segundo a policial, os vizinhos esperavam da polícia alguma atitude em relação à jovem, e fizeram uso do termo desaparecimento para acioná-la. Executando o que ela chama de serviço de "assistência social", a inspetora foi, em companhia do inspetor Fernando, até a casa onde o casal estaria vivendo, no intuito de averiguar se haveria entre eles uma relação de exploração. Constatou então que, embora a mulher estivesse de fato usufruindo dos bens do senhor, por outro lado, cuidava dele diariamente. A situação que, do ponto de vista dos vizinhos, seria de submissão do senhor em face da jovem, para a inspetora tratava-se de uma troca justa de favores, já que o homem não possuía familiares e/ou pessoas que dele cuidassem tão de perto.

Casos como este, nas palavras de Telma, não são problemas de polícia, e sim problemas de família, que devem ser solucionados por medidas que fogem ao alcance da polícia. Segundo a inspetora, desaparecimentos são experiências de pessoas que deixam suas casas, vizinhanças e comunidades em decorrência de circunstâncias e fatos de natureza familiar e privada nos quais a polícia não deve intervir, como seria o caso de Daniela, apresentado no começo deste texto. Aproximam-se, também neste sentido, de ocorrências de violência contra mulheres registradas nas DEAMs, por terem sua excepcionalidade e potencial gravidade rotineiramente negadas por meio da inscrição dos episódios no cotidiano de relações familiares (Enne, Vianna \& Carrara, 2002).

Esforçando-se por classificar a natureza do desaparecimento, relatos de policiais promovem não só a inscrição dos casos no plano das relações familiares 
mantidas pelos desaparecidos, mas também a divisão entre o que seriam propriamente problemas de polícia e tramas que não contam com componentes criminais. Nesse processo, contrapõem o que seriam problemas de família ao que lhes parece efetivamente atribuição da polícia, procurando depurar o que é de sua competência e responsabilidade e situar num polo oposto o que julgam ser de responsabilidade de unidades domésticas, parentelas, casas e outros conjuntos de pessoas que denominam, genericamente, como famílias. Desse modo, dão sentido ao arquivamento quase sumário de numerosos casos como, por exemplo, o de Daniela.

\section{Estruturando um problema social}

Casos relatados e arquivados por policiais do SDP, bem como depoimentos registrados em trabalhos sobre o tema (cf. Oliveira, D.D., 2007; Araújo, 2007), sugerem que nas DPs brasileiras o desaparecimento é objeto de atos de fala que, como as acusações de feitiçaria analisadas por Favret-Saada (1977), compõem um jogo de forças de caráter enunciativo em que responsabilidades são distribuídas. ${ }^{6}$ Nessas repartições, afinal, o desaparecimento é encarado como um tipo de ocorrência que foge ao escopo do trabalho policial e, portanto, que demanda competências e implica responsabilidades que se encontram fora das delegacias. Não obstante, outros atores sociais, como gestores de políticas públicas e representantes de ONGs que assistem a familiares de desaparecidos, contrapõem-se aos policiais e propõem outras concepções do desaparecimento, complexificando o jogo de forças movimentado em delegacias. Eventos da Rede Nacional de Identificação e Localização de Crianças Desaparecidas (ReDesap), nos quais também realizei trabalho de campo, são espaços que tornam esse jogo de forças especialmente nítido, uma vez que reúnem policiais, gestores e representantes dessas ONGs e de outras organizações.

Constituindo os polos desse jogo, membros da rede posicionam-se numa tríade bastante clara: numa ponta, os policiais, que enunciam sua visão dos casos como problemas de família também no âmbito da ReDesap; em outra ponta, gestores de políticas públicas, que amplificam essa classificação produzida por policiais, acrescentando a ela mais um componente: para eles, os casos não são simplesmente problemas de família, e sim problemas de famílias desestruturadas; por fim, numa terceira ponta, as mães de desaparecidos, que se apresentam como representantes autorizadas (Bourdieu, 1984) das famílias de desaparecidos. Reunidas em associações e ONGs, as mães se contrapõem a policiais e gestores, buscando sustentar que o desaparecimento é sim problema de polícia, embora seja também um problema do Estado. 
A seguir, descrevo a posição de cada uma das pontas dessa tríade. Argumento, então, que são os próprios embates estabelecidos entre elas que constituem o desaparecimento de pessoas como problema social. Conforme sugere Souza Lima (2002), na definição de categorias jurídico-normativas, políticas públicas e problemas sociais há mais que aplicação de regras, normas e procedimentos burocráticos a realidades supostamente dadas ao conhecimento e à intervenção. Importa, portanto, investigar os processos através dos quais categorias, políticas e problemas sociais conectam-se aos universos que buscam circunscrever (e, tantas vezes, transformar). A descrição das posições e dos embates entre membros da ReDesap descortina, nesse sentido, o processo por meio do qual o problema do desaparecimento conecta-se a casos particulares de ausência de pessoas em seus círculos de relações.

\section{"Há famílias desestruturadas em todas as classes sociais"}

Representando órgãos e programas nacionais, estaduais e municipais de diferentes ministérios e secretarias, gestores de políticas públicas das áreas de Direitos Humanos, Assistência Social, Segurança Pública e Relações Internacionais compartilham não só a mesma abordagem quanto a causas e formas de combater o desaparecimento, mas também a mesma maneira de se apresentarem diante de outros participantes de encontros da ReDesap. Somam-se a eles, compartilhando a mesma abordagem, servidores de órgãos do Judiciário e conselheiros tutelares e dos direitos da criança e do adolescente. Recorrendo ao mesmo número e estatística, suas falas colocam-se como diagnósticos da questão, avaliações do que deve ser feito para preveni-la e, por fim, um agregado de alertas. Pronunciam, nos termos de Boltanski (1993), "enunciados de saberes", caracterizados por suprimirem singularidades em prol da produção de afirmações categóricas e supostamente verificáveis.

Situando-se no plano da generalidade política, gestores recorrem reiteradamente ao mesmo conjunto de dados estatísticos e raras vezes narram ou citam casos específicos. Nem mesmo casos célebres, que são frequentemente objeto de referência em conversas mantidas durante os eventos da rede, comparecem em seus enunciados. ${ }^{7}$ Segundo números evocados por gestores, sempre sem citação de fontes, 40 mil crianças e adolescentes desaparecem anualmente no Brasil. Deste total, cerca de 75\% dos casos consistem em fugas de crianças que sofrem violência e castigos físicos dentro de suas casas e, por isso, preferem viver nas ruas e/ou em abrigos públicos. Esse entendimento é de tal forma consolidado que muitos gestores utilizam indiferenciadamente os termos desaparecimento e fuga, tratando-os como equivalentes. Contudo, para eles, aquela cifra não significa que famílias particulares sejam culpabilizáveis pelos desaparecimentos. 
Esforçando-se por deslocar responsabilidades atribuídas diretamente a famílias particulares, gestores sustentam que as raízes do desaparecimento residem no atual "descuido de relações e crescente individualismo", que viriam acompanhando o "fim da família extensa e das redes comunitárias e o predomínio da família monoparental chefiada por mulheres", que faria recair sobre os ombros de mães solteiras o dever do cuidado e da disciplina de seus filhos. Suas falas, nesse sentido, evocam mais um modelo singular de família supostamente perdido, e menos os múltiplos arranjos domésticos em que ocorrem casos de desaparecimento. O ocaso desse modelo de família desdobra-se, no Brasil contemporâneo, em relações familiares tensas e violentas que, por sua vez, geram desaparecimentos. Nesse cenário, alguns personagens ganham contornos claros: o pai ausente, a mãe sobrecarregada que chefia a família e é violenta com sua prole e, por fim, o filho que deseja fugir. O filho que deseja fugir seria encarnado pelas 40.000 crianças e adolescentes que desaparecem anualmente no Brasil.

Assim entendido o desaparecimento, fundamentalmente as formas de prevenção a serem adotadas devem ser dirigidas a famílias e comunidades. Em função disso, muitos gestores descrevem os limites e as possibilidades abertas por serviços públicos de assistência social, políticas públicas voltadas para crianças e adolescentes "em situação de risco" e "em situação de rua" e, principalmente, pelo Plano Nacional de Convivência Familiar e Comunitária (PNCFC) ${ }^{8}$ Citando trechos do Plano e enaltecendo aspectos de diversas políticas e serviços públicos, gestores frisam que é preciso que haja maior integração das políticas sociais brasileiras para que famílias sejam plenamente assistidas. Ademais, defendem que "boas práticas" desenvolvidas por ONGs devem ser valorizadas, e reafirmam a importância de programas de reintegração de crianças e adolescentes fugidos a suas famílias. Tornando possível essa reintegração, abrigos e outras medidas temporárias de acolhimento seriam de fato temporários, já que as famílias estariam mais bem preparadas para receber e proteger seus filhos.

Por fim, gestores afirmam repetida e enfaticamente que para combater as causas do desaparecimento é preciso dissociá-lo do fenômeno da pobreza. Para eles, castigos físicos e psicológicos, entre outras formas de violência, não ocorrem apenas nas camadas pobres da sociedade. Por conseguinte, desaparecimentos também não se confinam em tais porções da população. Esse entendimento foi condensado em frase marcante proferida em um dos eventos nacionais da rede: "há famílias desestruturadas em todas as classes sociais". Segundo esta perspectiva, o que se tem no Brasil contemporâneo é a ausência de uma família que proteja suas crianças e adolescentes. Vítimas de processos que as transcendem, famílias particulares em que há violência, castigos físicos e relações 
conflituosas, independente da classe social em que possam ser indexadas, ao não protegerem suas crianças e adolescentes, provocam suas fugas de casa. São tais fugas que constituem casos de desaparecimento.

\section{"Minha família se desestruturou depois que minha filha desapareceu"}

Embora apenas uma delas componha o comitê gestor da rede, três mães de desaparecidos fazem-se ouvir repetidas vezes nos encontros da ReDesap: Cecília, Maria e Flávia. As três fundaram, após o desaparecimento de seus filhos, ONGs dedicadas a prestar assistência a familiares de desaparecidos, localizar desaparecidos e/ou atuar na prevenção de novos casos. São conhecidas de muitos membros da rede, que as citam e evocam reiteradamente não só através de referências a seus nomes e/ou aos nomes das ONGs que fundaram, mas também por meio de citações dos nomes de seus filhos desaparecidos. ${ }^{9}$

Em 1996, Cecília e Maria fundaram, juntas, a ONG que hoje é presidida por Cecília. Em 2005, Maria deixou a ONG e fundou uma segunda organização, na mesma cidade. Já Flávia é conhecida entre os membros da rede como a pioneira no enfrentamento de desaparecimento de crianças e adolescentes. Flávia fundou uma associação para assistir a famílias e promover medidas de prevenção do desaparecimento de crianças e adolescentes, em funcionamento desde 1991, e seguiu carreira política, tendo sido eleita vereadora e deputada estadual. Embora Cecília, Maria e Flávia tenham lugar de destaque na ReDesap, outras mães, criadoras e integrantes de associações e ONGs que não as fundadas pelas três, também participam dos encontros. Com raras exceções, todas iniciam seus pronunciamentos narrando os desaparecimentos de seus filhos. Não obstante, suas narrativas são compostas tanto por alusões às suas relações com eles quanto por descrições de interações com policiais e, em alguns casos, funcionários de outras repartições públicas.

Diferente dos gestores, mães não destacam estatísticas nem apresentam diagnósticos acerca do desaparecimento. Emitindo "enunciados de opinião", e não "enunciados de saberes" (Boltanski, 1993), seus relatos são construídos na primeira pessoa (ora do singular, ora do plural) e apresentam suas trajetórias como mães, como parte de famílias vitimadas pelo mesmo infortúnio e, a partir daí, como fundadoras de instituições que buscam suprir a falta de assistência que cada uma delas enfrentou ao vivenciar o desaparecimento de um filho. "Enunciados de opinião" carregam afirmações originais, derivadas de experiências singulares, e emitem julgamentos indissociáveis do sujeito da enunciação e de sua perspectiva (Boltanski, 1993:87). Fazendo uso do que Boltanski (1993) 
designa "estilo emotivo", as mães inscrevem-se em seus enunciados, tornandose elas próprias objeto de suas falas, e afirmam que a razão inicial de seu engajamento na causa do desaparecimento reside em suas experiências pessoais de sofrimento. Contudo, repetidas vezes sustentam que seguem mobilizadas não apenas em função de suas próprias experiências, e sim em nome de outras mães de desaparecidos. Como disse Cecília em um encontro nacional da rede: "Eu descobri que vim lutar não só por mim, mas por todas as mães, porque me sinto mãe de cada uma delas".

Cecília refere-se às mães de desaparecidos atendidas pela ONG que fundou como "minhas mães" e "minhas mãezinhas". Reconhecida por sua já longeva atuação à frente da ONG e também por "falar bem”, "falar bonito" (cf. Comerford, 1999:93), e proferir palestras sempre comovidas e comoventes, Cecília cumpre papel de porta-voz autorizada das mães de pessoas de desaparecidas. Colocandose como representante desse grupo, o institui (Bourdieu, 1984).

As mães identificam a omissão de agentes responsáveis por assistir a famílias de desaparecidos como a principal causa do fenômeno. De seu ponto de vista, pela falta da assistência que lhes deveria ser prestada pelo Estado e, também, pela ausência de uma atuação sensível e adequada por parte da polícia, suas famílias se desestruturaram ao vivenciar o desaparecimento de um de seus membros. Contrapondo-se à perspectiva dos gestores, afirmam reiteradamente que “o desaparecimento não acontece porque a família é desestruturada”. Invertendo os termos dessa equação, relatam que seus casamentos foram devastados, outros filhos foram afetados e suas contas bancárias acabaram "zeradas” em função do desaparecimento de seus filhos. Enfatizando que sempre foram provedoras de "bens de cuidado" (Vianna, 2002) no limite do possível, situam o desaparecimento de seus filhos como pontos de inflexão que as desviaram de uma vida familiar plena para um tortuoso caminho de sofrimento. ${ }^{10}$ Nas palavras de Maria, para as mães "não importa se a criança fugiu de casa, o Estado tem que se responsabilizar. Eu pergunto há 13 anos para o Estado onde está minha filha. O Estado me deve a minha filha”.

A ausência desse Estado devedor manifesta-se, do ponto de vista das mães, sobretudo na inexistência de legislação pertinente que regule a gestão e o enfrentamento de casos, de serviços de assistência social de qualidade à disposição das famílias, e de tecnologia à disposição da polícia (sistemas de informação, bancos de DNA e sistemas de envelhecimento de fotografias que auxiliariam as investigações de casos). A essas faltas soma-se, ainda, outra ausência de que as mães se queixam enfaticamente: a falta de sensibilidade, conhecimento e capacidade para lidar com o desaparecimento característica de policiais. 
Eventos da ReDesap servem às mães como instâncias em que compartilham e denunciam a inadequação do atendimento que receberam em delegacias quando do desaparecimento de seus filhos. Muitas relatam ter sido orientadas a retornar às delegacias 48 horas depois da constatação do desaparecimento, sustentando que se faz presente entre policiais o chamado "mito das 48 horas": a praxe de impor uma espera de dois dias como condição para produzir o registro do caso. ${ }^{11}$ Segundo as mães, este mito evidencia a desconfiança com que foram e são recebidas em delegacias, onde "sempre pensam que nossos filhos saíram de casa por motivos ruins ou por nossa culpa, e que não voltam porque não querem”, como afirma Maria. A imposição da espera, nesse sentido, seria um recurso de que policiais lançam mão não só para se isentarem de responsabilidades diante dos casos, mas também para explicitarem seu entendimento dos mesmos como problemas de família.

Para as mães, é fundamental que o registro seja feito o mais próximo possível da data e hora do desaparecimento, em função de se iniciarem investigações o quanto antes e pela importância de que gozam os documentos no Brasil (cf. Peirano, 2006). Especificamente em casos de desaparecimento, ademais, providenciar o registro do caso de um filho é, para as mães, fornecer um "bem de cuidado" (Vianna, 2002) ao desaparecido, materializando, na forma de datas e horários documentados, que elas não são "boas mães" apenas quando têm seus filhos próximos de si.

Do prisma das mães, o tempo é um dos grandes inimigos de todos aqueles que buscam desaparecidos - e não só o tempo da espera imposta em delegacias. Os efeitos do "mito das 48 horas", assim como da desconfiança de policiais em relação a elas, seriam agravados pela passagem do tempo. Em diferentes reuniões da rede, presenciei mães interpelando policiais e indagando-lhes "o que acontece com as investigações dos casos com a passagem dos anos?”. Perguntas como esta, que denunciam a possibilidade de arquivamento sumário de casos em delegacias, revelam o descompasso entre temporalidades inerente a encontros entre cidadãos e funcionários de repartições burocráticas (Herzfeld, 1992), experimentado com apreensão pelas mães. Como adverte Das (2007), encontros burocráticos não apenas reúnem temporalidades distintas, como fazem com que o tempo da burocracia incida sobre o tempo da dor pessoal.

Para as mães, em suma, o desaparecimento evidencia a ausência do Estado nas vidas daqueles que necessitam de assistência seja para cuidar, seja para localizar seus filhos. Não obstante, o sofrimento que o fenômeno causa é ainda agravado pela maneira como policiais agem diante delas e de seus relatos. De seu ponto de vista, para caracterizar a atuação da "polícia” diante do fenômeno, melhor seria falar em omissão, indiferença e inação. 


\section{"Não temos a estrutura necessária"}

Representando delegacias e setores das Polícias Civis de diferentes unidades da federação, delegados e agentes de polícia constituem a vasta maioria dos participantes dos encontros e reuniões promovidos pela ReDesap. O fato de muitos comparecerem aos encontros vestidos com camisetas indicativas da Polícia Civil de seus estados torna isto facilmente perceptível. Contudo, poucos policiais proferem falas programadas e integram mesas oficiais nos eventos da rede. Sua participação se dá principalmente como debatedores de pronunciamentos feitos por outrem e em contatos mais próximos entre si, firmados nos intervalos e entreatos dos encontros. Enquanto gestores fazem diagnósticos eloquentes e emitem enunciados categóricos sobre o desaparecimento e mães narram suas comoventes experiências de sofrimento, policiais ocupam uma peculiar posição de recuo e autodefesa nos encontros.

As falas de policiais são, em geral, mais curtas e diretas que os relatos pessoais das mães e que as afirmações categóricas dos gestores. O mote central de seus pronunciamentos é o reconhecimento de que é preciso modificar a maneira como agentes e repartições policiais lidam com o desaparecimento, sobretudo em função dos relatos de atendimentos frustrantes feitos pelas mães ao se referirem a delegacias. Afirmam repetidas vezes que a troca de experiências entre policiais de estados diferentes é fundamental para que medidas bem-sucedidas possam ser replicadas.

Muitas vezes restringindo-se a responder às mães e, em algumas ocasiões, pedindo-lhes expressamente desculpas pelos episódios por elas vividos em delegacias, de forma sintética, os policiais a um só tempo responsabilizam-se e eximem-se de responsabilidades pela forma como lidam com casos de desaparecimento. Também recorrendo ao "estilo emotivo" (Boltanski, 1993), colocam-se como objeto de suas próprias enunciações. Afirmando que em geral não sabem como lidar com o fenômeno, desconhecem suas causas e não são treinados para enfrentar a vulnerabilidade das famílias, sustentam que o obstáculo central a ser superado é a ausência do tema nos cursos de formação oferecidos pelas Academias de Polícia e a inexistência de modelos de investigação de casos de desaparecimento. Nas palavras de um delegado, proferidas em um dos encontros nacionais da rede, "a gente vem aqui de público fazer um mea culpa diante das mães, mas de fato a maior parte dos policiais não sabe como lidar com o desaparecimento".

De modo análogo aos gestores, que apontam como causa de desaparecimentos um fenômeno geral que recai sobre famílias particulares, policiais falam de uma ampla falta de conhecimento e meios de investigação como característica 
geral da polícia, que incidiria especificamente sobre cada um deles e cada repartição policial, engendrando o tratamento inadequado dos casos. Intercorrências nos atendimentos a familiares de desaparecidos ou nas investigações de desaparecimentos dizem respeito, para eles, não a seus desempenhos individuais como policiais, e sim a processos relativamente autônomos, sobre os quais não têm controle, e dos quais são vítimas.

Do ponto de vista dos policiais que participam dos encontros da ReDesap, o desaparecimento é questão mal administrada nas delegacias em função de três ausências específicas: o tema não consta dos cursos de formação e capacitação de policiais, não é objeto de instrumentos legais adequados, e muitas delegacias não possuem os meios necessários para investigar casos com celeridade. A falta de viaturas, computadores, sistemas de informação, tecnologia e de outros bens imprescindíveis ao seu trabalho seria, para eles, razão fundamental da maneira falha com que a polícia tem lidado com os casos. Nos termos de uma delegada, "não temos a estrutura necessária e estamos órfãos dentro da polícia”. Enquanto as mães que fundam instituições, como diz Cecília, sentem-se mães de todas as mães que por elas procuram, policiais sentem-se órfãos diante de casos de desaparecimento. ${ }^{12}$ Se não prestam serviços adequados a famílias, isto se deve, portanto, à sua própria experiência de orfandade "dentro da polícia”: uma espécie de falta de pais metafóricos e quase demiúrgicos, que lhes devem certo tipo de provisão fundamental para que executem seu trabalho. Em suma, essa orfandade indica a ausência do que deveria necessariamente ser fornecido por outrem a eles e às repartições em que estão lotados: a soma do que chamam de "estrutura", de "legislação adequada" e de "conhecimento".

A essas faltas deve ainda ser acrescentado, segundo os policiais, o fato de que famílias de pessoas que retornam às suas casas frequentemente não notificam a volta do desaparecido. Por esta razão, muitas investigações restam abertas, embora os casos já estejam solucionados. Este seria um indício de que, nos termos de um delegado, "as famílias fornecem informações precárias e dificultam o trabalho policial”. Portanto, ainda que peçam desculpas às mães por atendimentos pouco respeitosos ou ineficazes, policiais também afirmam que parte das dificuldades de se lidar com o desaparecimento decorre da maneira como as famílias se aproximam da polícia. Se, conforme enunciam as mães, a polícia atua de forma omissa, desrespeitosa e indiferente, para os policiais tal atuação se faz em mão dupla. Somando-se suas perspectivas, nota-se, assim, que o encontro de polícia e famílias engendra o crescente distanciamento entre pessoas inscritas nestes dois grupos, instituídos como unidades facilmente diferenciáveis e tipificáveis, e perpetua estereótipos e "convenções de desdém” (Herzfeld, 1992) construídas por ambos a respeito uns dos outros e de suas condutas. ${ }^{13}$ 


\section{Considerações finais}

A análise de Boltanski (1993) sobre conexões entre piedade, compaixão e engajamento revela que formas de compadecimento diante de episódios de sofrimento desempenham papel central no estabelecimento de laços sociais e políticos. Precipitando-se em causas pelas quais é moralmente imperativo mobilizar-se, a exibição de experiências de sofrimento engendra a modulação de enunciados, a delimitação de grupos e a identificação, em processos variados, de "vítimas", "espectadores" e "agentes" implicados em episódios de sofrimento (Boltanski, 1993:95).

Casos de desaparecimento de pessoas comparecem em pronunciamentos de mães de desaparecidos como episódios causadores de sofrimento que exigem empatia, mobilização e comprometimento por parte de múltiplos agentes. $\mathrm{O}$ mesmo se dá em falas de gestores e policiais, a despeito da raridade com que tomam casos singulares como objeto de seus enunciados. Conforme indicam as posições destes três grupos em encontros da ReDesap, casos particulares, subsumidos pela questão geral do desaparecimento, permitem identificar "vítimas" e "agentes" de sofrimento, bem como "agentes" capazes de combatê-los. Contudo, policiais, gestores e mães de desaparecidos identificam de modo bastante distinto quem são as "vítimas" e os "agentes" do sofrimento específico causado pelo desaparecimento.

Distribuindo responsabilidades, gestores diagnosticam o desaparecimento como problema decorrente da ausência de uma família que proteja seus membros. Já para mães de desaparecidos, o desaparecimento deve ser encarado como consequência da ausência de um Estado que disponibilize redes de assistência social de qualidade e serviços policiais sensíveis e competentes para prevenir e solucionar casos como os de seus filhos. Para policiais, finalmente, o fenômeno é objeto de desconhecimento e, se recebe tratamento inadequado, isto se deve à ausência de saberes e meios materiais necessários à boa investigação dos casos no interior de repartições policiais. No entrelaçamento de tantas ausências, tecido pelo embate e pelas responsabilizações cruzadas entre esses agentes, o problema do desaparecimento é construído como um vazio plural, no qual está inscrita também, mas não apenas, a ausência do desaparecido.

Vale destacar que os grupos que se engajam nessas denúncias de múltiplas ausências desempenham papéis distintos na construção do desaparecimento como problema social. Policiais, embora sejam maioria tanto na composição quanto nos encontros da rede, colocam-se em posição defensiva e recuada, justificando o atendimento inadequado que fornecem às famílias e pedindo desculpas às mães de desaparecidos. Gestores, por sua vez, colocam-se em posição relativamente 
mais distante das mães e dos policiais, dedicando-se a construir diagnósticos do problema sem, contudo, examinar casos singulares.

Já as mães, ao construírem seu lugar de enunciação a partir dos episódios de sofrimento que experimentaram, articulam casos singulares de desaparecimento e mau atendimento em delegacias com o patamar da generalidade política em que se situam os enunciados dos gestores. São elas que produzem a "associação entre descrição e comoção" (Boltanski, 1993:17) essencial para a construção de causas, nas quais agentes sociais engajam-se a despeito da distância que guardam em relação a sofrimentos individuais. Nesse sentido, a forma como expressam emoções causadas pelo desaparecimento de seus filhos e pelos encontros burocráticos que o sucederam cumpre papel decisivo na produção de sua credibilidade diante de membros da ReDesap. Conforme mostra Bailey (1983), formas de expressar emoções em arenas políticas podem revestir sujeitos de credibilidade ou, pelo avesso, de descrédito. Em eventos da rede, o "estilo emotivo" (Boltanski, 1993) das mães lhes confere não só credibilidade, mas também distinção.

As emoções formuladas e provocadas pelas mães de desaparecidos desempenham papel decisivo na construção de sua credibilidade e, principalmente, da credibilidade do próprio desaparecimento de pessoas como problema social, que deve ser reconhecido e enfrentado como tal. Se gestores colocam mães no lugar de chefia de certo tipo de família que, com frequência, produz desaparecimentos, as mães de desaparecidos não só negam esse lugar, como também ocupam posição central na construção do desaparecimento como causa. Da forma como se colocam nos encontros da rede, são elas que dão corpo à conversão dos desaparecimentos de seus filhos em manifestações particulares do problema social que denunciam. Falando e mostrando a dor que sentem, dão testemunho do mal causado não apenas a elas, mas ao tecido social como um todo (Das, 2007:59-60).

Em síntese, o vazio que constrói o desaparecimento de pessoas como problema social não traduz apenas a falta do desaparecido em meio aos que por ele buscam. Sem dúvida, essa ausência impacta, de formas variadas, todos os envolvidos em casos particulares. Entretanto, reuniões e encontros da ReDesap sugerem que outras ausências fazem da falta da pessoa desaparecida a manifestação particular do problema do desaparecimento. A relação entre cada caso e o problema do desaparecimento, nesse sentido, não consiste simplesmente na dupla parte versus todo. Em vez disso, cada caso se torna parte do problema social mais amplo por ser encarado como consequência de um conjunto maior de faltas: a ausência de um Estado assistente, a ausência de uma polícia sensível e competente e, ainda, a ausência de uma família protetora. 
Recebido em 20/10/2013

Aceito em 14/02/2013

Letícia Carvalho de Mesquita Ferreira é doutora em Antropologia Social pelo PPGAS/Museu Nacional/UFRJ, e atualmente professora adjunta da Escola de Ciências Sociais/CPDOC da Fundação Getúlio Vargas. Principais temas de interesse: antropologia do Estado; etnografia de elites, redes e dispositivos de poder; práticas estatais de identificação e documentação. 


\section{Notas}

1. Para preservar as identidades das pessoas junto às quais realizei a pesquisa que deu origem ao presente artigo, todos os nomes próprios a que faço referência são fictícios.

2. Diferenciando-se de outros autores, Oliveira (2007) faz uso dos termos desaparecidos civis, e não apenas desaparecidos, de modo a distinguir casos contemporâneos dos chamados desaparecimentos políticos, tipificados pelo Direito Internacional como desaparecimentos forçados de pessoa.Definido no âmbito do Tribunal Penal Internacional em abril de 1998, e regulado pelo chamado Estatuto de Roma, por desaparecimento forçado de pessoas entendese "a prisão, detenção ou sequestro de pessoas por um Estado ou por organização política, ou com a autorização, apoio ou aquiescência destes, seguidos da negativa de informar sobre a privação de liberdade ou dar informação sobre a sorte ou o paradeiro dessas pessoas, com a intenção de deixá-las fora do amparo da lei por um período prolongado. Esse conceito foi mantido no Estatuto definitivo, enquanto crime contra a humanidade.” (Jardim, 2011:14).

3. A definição de problema social aqui empregada baseia-se na discussão de Sayad (1998) em torno do estatuto do imigrante e da imigração, respectivamente personagem e fenômeno nomeados em termos dos problemas a que são associados. Nas palavras do autor, "Está no estatuto do imigrante [...] e, por conseguinte, na própria natureza da imigração, só poderem ser nomeados, só poderem ser captados e tratados através dos diferentes problemas a que se encontram associados - problemas que se devem entender aqui no sentido de dificuldades, distúrbios, danos etc., mais do que no sentido de problemática constituída de forma crítica em relação a um objeto que cria necessariamente um problema e que, característica esta que lhe é própria, existe apenas, no limite, graças aos problemas que coloca para a sociedade" (:15).

4. Para uma definição de etnografia multissituada, ver Marcus (1995).

5. Sobre a instauração e a condução de inquéritos policiais na Polícia Civil do Rio de Janeiro, ver Kant de Lima (1995), Miranda et al. (2010) e Misse (2011).

6. Inspiradores para se pensarem embates enunciativos em torno de responsabilidades e competências, os casos de acusação de feitiço apresentados por Favret-Saada (1977) evidenciam que a feitiçaria consiste num jogo de forças de caráter discursivo, por meio do qual diferentes atores se colocam em posições relacionais, atribuindo a seus interlocutores e a terceiros posições específicas por meio de atos de fala (paroles). De cada situação particular em que este jogo de forças se faz presente, ou seja, em cada caso de feitiçaria, emerge uma configuração específica em que um sujeito é acusado de feiticeiro, sendo visto como portador de uma capacidade extraordinária que o torna hábil a causar infortúnios em série à vida alheia. Nessa configuração, o desenfeitiçador (désorceleur) comparece como sujeito dotado de competências específicas que o facultam a interromper aquela série de infortúnios.

7. Membros da rede frequentemente fazem referência a casos célebres, que teriam 
sido objeto de ampla divulgação e repercussão, e que compõem um imaginário comum (Boltanski, 1993): “o caso Pedrinho”, “o caso Carlinhos” e o “o caso Madeleine”. Este último diz respeito a uma menina inglesa que desapareceu em um hotel na Praia da Luz, em Portugal, na noite de 3 de maio de 2007. "Caso Carlinhos", por sua vez, refere-se ao sequestro de um menino na noite de 2 de agosto de 1973, no Rio de Janeiro. Por fim, “o caso Pedrinho" diz respeito à subtração de incapaz, em que um bebê foi levado da maternidade em 21 de janeiro de 1986, em Brasília, por uma mulher que o registrou como seu filho e o criou em Goiânia.

8. Instituído em 2006, o plano é apresentado como "um marco nas políticas públicas no Brasil, ao romper com a cultura da institucionalização de crianças e adolescentes e ao fortalecer o paradigma da proteção integral e da preservação dos vínculos familiares e comunitários preconizados pelo Estatuto da Criança e do Adolescente. A manutenção dos vínculos familiares e comunitários - fundamentais para a estruturação de crianças e adolescentes como sujeitos e cidadãos - está diretamente relacionada ao investimento nas políticas públicas de atenção à família” (BRASIL, 2006:17).

9. Sobre a relação entre maternidade e atuação em movimentos sociais, associações e ONGs, ver Leite (2004), Araújo (2007) e Vianna \& Farias (2011).

10. Bens de cuidado são bens simbólicos do cuidar, que "representam sinais do investimento que pode ser calculado e, ao mesmo tempo, que nunca pode ser expresso claramente em termos materiais, já que serve de indicativo da ação desinteressada que não espera pagamento imediato ou não o espera na mesma moeda” (Vianna, 2002:203). Bens simbólicos que são, a atribuição de seu valor depende em larga medida do contexto em que circulam. Especificamente no caso tratado por Vianna (2002), “bens de cuidado” são listados e apresentados em processos judiciais de guarda de crianças e adolescentes.

11. Para casos envolvendo crianças e adolescentes, a imposição da espera é não só desprovida de respaldo, mas também ilegal. Conhecida pelos membros da rede como "Lei da Busca Imediata”, desde 2005 vige no Brasil a Lei 11.259/2005, que determina que "A investigação do desaparecimento de crianças ou adolescentes será realizada imediatamente após notificação aos órgãos competentes, que deverão comunicar o fato aos portos, aeroportos, Polícia Rodoviária e companhias de transporte interestaduais e internacionais, fornecendo-lhes todos os dados necessários à identificação do desaparecido" (BRASIL, 2005). Esta lei foi incorporada ao Artigo 208 do Estatuto da Criança e do Adolescente (Lei 8.069/1990).

12. Para uma reflexão sobre o amplo uso de metáforas de família e parentesco a que o autor denomina "retórica do Estado", e ainda sobre o aparente paradoxo entre o emprego de tais metáforas e a convencional rejeição ao chamado "familismo", ver Herzfeld (1992).

13. A circulação de estereótipos entre atores e sua mútua concepção como unidades estanques e facilmente tipificáveis são traços característicos de encontros burocráticos, 
conforme apontado por Herzfeld (1992), que se faz presente nas falas sobre o atendimento de mães e famílias por policiais. Nas palavras do autor, "the art of bureaucrat game-playing, whether from client to bureaucrat or the other way about, lies in essentializing one's own actions as logical on the strongly implied grounds that they rest on eternally valid rights or self-evidence. The other side's actions, by contrast, are capricious and irrational, based on personal or cultural flaws, and wrongheaded" (Herzfeld, 1992:86). 


\section{Referências}

ARAÚJJ, Fábio Alves. 2007. Do luto à luta: a experiência das Mães de Acari. Dissertação de Mestrado em Sociologia e Antropologia, Instituto de Filosofia e Ciências Sociais, UFRJ.

BRASIL. 2006. Presidência da República. Secretaria Especial dos Direitos Humanos. Conselho Nacional dos Direitos da Criança e do Adolescente. Plano Nacional de Promoção, Proteção e Defesa do Direito de Crianças e Adolescentes à Convivência Familiar e Comunitárial Secretaria Especial dos Direitos Humanos. Brasília: Conanda.

BRASIL. 2005. Presidência da República. Lei $N^{\circ}$. 11.259, de 30 de dezembro de 2005. Brasília: Presidência da República.

BRASIL, 2010. Câmara dos Deputados. Comissão Parlamentar de Inquérito destinada a investigar as causas, as consequências e os responsáveis pelo desaparecimento de crianças e adolescentes no Brasil, no período de 2005 a 2007. Relatório Final.

BOLTANSKI, Luc. 1993. La souffrance à distance: morale humanitaire, médias et politique. Paris: Gallimard.

BOURDIEU, Pierre. 1984. "La délégation et le fetichisme politique“. Actes de la Recherche en Sciences Sociales, 52-53:49-55.

ENNE, Ana Lúcia; VIANNA, Adriana R.B.\& CARRARA, Sérgio. 2002. "Entre o Crime e a Conciliação: a violência contra a mulher na justiça do Rio de Janeiro”. Acervo. Revista do Arquivo Nacional, 15(1): 39-58.

ESPINHEIRA, Gey. 1999. Desaparecimento e desaparecidos: um estudo de violência urbana. Salvador: CEFIJ.

FAVRET-SAADA, Jeanne. 1977. Les mots, la mort, les sort. Paris: Éditions Gallimard.

FERREIRA, Letícia Carvalho de Mesquita. 2011.Uma etnografia para muitas ausências: o desaparecimento de pessoas como ocorrência policial e problema social. Tese de Doutorado em Antropologia Social, Programa de Pós-Graduação em Antropologia Social do Museu Nacional/UFRJ.

HERZFELD, Michael. 1992. The Social Production of Indifference: exploring the symbolic roots of western bureaucracy. Chicago: The University of Chicago Press.

JARDIM, Tarciso Dal Maso. 2011. Brasil condenado a legislar pela Corte Interamericana de Direitos Humanos: da obrigação de tipificar o crime de desaparecimento forçado de pessoas. Brasília: Centro de Estudos da Consultoria do Senado/Textos para discussão, n. 83, janeiro. 
KANT DE LIMA, Roberto. 1995. A polícia da cidade do Rio de Janeiro: seus dilemas e paradoxos. Rio de Janeiro: Editora Forense.

LEITE, Márcia. 2004. "As mães em movimento”. In: M. Leite \& P. Birman (orgs). Um mural para a dor: movimentos cívico-religiosos por justiça e paz. Porto Alegre: Editora da UFRGS. pp.141-190.

MARCUS, George E. 1995. "Ethnography in/of the world system: the emergence of Multi-Sited Ethnography”. Annual Review of Anthropology, 24:95-117.

MIRANDA, Ana Paula Mendes de et al. 2010. “A reinvenção da 'cartorialização': análise do trabalho policial em registros de ocorrência e inquéritos policiais em 'Delegacias Legais' referentes a homicídios dolosos na cidade do Rio de Janeiro”. Segurança, Justiça e Cidadania, 4:119-152.

MISSE, Michel. 2011. "O Papel do Inquérito Policial no Processo de Incriminação no Brasil: algumas reflexões a partir de uma pesquisa”. Revista Sociedade e Estado, 26(1):15-27.

MOTA, Paula Poncioni. 1995. A polícia e os pobres: representações sociais e práticas em delegacias de polícia no Rio de Janeiro. Dissertação de Mestrado em Serviço Social, Escola de Serviço Social, Universidade Federal do Rio de Janeiro.

NOBRE, Carlos. 2005. Mães de Acari: uma história de protagonismo social. Rio de Janeiro: Ed. PUC-Rio/Pallas.

OLIVEIRA, Dijaci David \& GERALDES, Elen Cristina. 1999. Cadê Você. Brasília: Movimento Nacional de Direitos Humanos.

OLIVEIRA, Dijaci David. 2007. “Desaparecidos” civis: conflitos familiares, institucionais e de segurança pública. Tese de Doutorado em Sociologia, Instituto de Ciências Sociais, Departamento de Sociologia, UnB.

OLIVEIRA, Sandra Rodrigues de.2008. Onde está você agora além de aqui, dentro de mim? O luto das mães de crianças desaparecidas. Dissertação de Mestrado em Psicologia, Departamento de Psicologia, PUC-Rio.

PEIRANO, Mariza. 2006. "De que serve um documento?”. In: Moacir Palmeira \& César Barreira (orgs). Política no Brasil: visões de antropólogos. Rio de Janeiro: Relume Dumará/ $\mathrm{NuAP} / \mathrm{UFRJ}$.

RIO DE JANEIRO. 1991. Secretaria de Estado de Segurança Pública. Resolução SEPC 513 de 16 de dezembro de 1991. Rio de Janeiro: Secretaria de Estado de Segurança Pública.

SAYAD, Abdelmalek. 1998. A Imigração: ou os paradoxos da alteridade. São Paulo: EdUSP. 
SOARES, Bárbara Musumeci.1999. Mulheres invisíveis: violência conjugal e novas políticas de Segurança. Rio de Janeiro: Civilização Brasileira.

SOARES, Gláucio Ary Dillon et al. 2006. As vítimas ocultas da violência na cidade do Rio de Janeiro. Rio de Janeiro: Civilização Brasileira.

SOUZA LIMA, Antonio Carlos de (org.). 2002. Gestar e gerir: estudos para uma antropologia da administração pública no Brasil. Rio de Janeiro: NuAP/Relume Dumará.

VIANNA, Adriana de R. B. 2002. Os limites da menoridade: responsabilidade, tutela e família em julgamento. Tese de Doutorado em Antropologia Social,Programa de Pós-Graduação em Antropologia Social do Museu Nacional/UFRJ.

VIANNA, Adriana\& FARIAS, Juliana. 2011."A guerra das mães: dor e política em situações de violência institucional”. Cadernos Pagu, 37:79-116.

\section{Documentos}

Setor de Descoberta de Paradeiros da Delegacia de Homicídios do Rio de Janeiro Centro/ Capital (SDP/DH) 


\section{Resumo}

$\mathrm{O}$ artigo tem por objetivo compreender a construção do desaparecimento de pessoas como um problema social que acomete o Brasil contemporâneo. Levando em conta a classificação de casos de desparecimento em delegacias de polícia como "problemas de família" e ocorrências de menor importância, propõe-se a analisar como esse fenômeno ganha o estatuto de questão grave, urgente e que demanda engajamento por parte de diferentes atores sociais e órgãos de administração pública. A hipótese sustentada é a de que a controvérsia em torno da natureza do fenômeno, estabelecida entre policiais, mães de pessoas desaparecidas e gestores de políticas públicas, é o que constitui o desaparecimento como problema social. O texto é fruto de pesquisa etnográfica multissituada, iniciada em um setor da Polícia Civil do Rio de Janeiro especializado em casos de desaparecimento e estendida para eventos de uma rede que reúne organizações governamentais e não governamentais que lidam com a questão.

Palavras-chave: Desaparecimento de pessoas, problema social, família, polícia, Estado

\section{Abstract}

The paper aims at understanding how the missing persons issue is constituted as a social issue that affects contemporary Brazil. Taking into account the classification of missing persons cases in police stations as "family issues" and instances of minor importance, it examines how this phenomenon attains the status of a serious issue, demanding urgent commitment by different social actors and public agencies. It poses the hypotheses that the controversy surrounding the nature of the phenomenon, established among police officers, mothers of missing persons and policymakers, is what turns it into a social issue. The paper is a result of a multi-sited ethnography, initiated in a sector of the Civil Police of Rio de Janeiro and extended to public events organized by a network that brings together governmental and non-governmental organizations dealing with the issue.

Keywords: Missing persons, social issue, family, police, State 